\title{
MERCADO INTERNACIONAL DE CARNE VACUNA: EVOLUCIÓN RECIENTE DE LOS FLUJOS COMERCIALES Y SITUACIÓN DE ARGENTINA ${ }^{1}$
}

\author{
Carlos Alonso* \\ Carolina Szpak**
}

Resumen. El presente artículo detalla el comercio mundial de carne vacuna en el período 2006-2015. El análisis de los flujos comerciales permite identificar la existencia de importantes jugadores a nivel país, cierta concentración de mercado tanto desde la oferta como desde la demanda en todas las posiciones arancelarias involucradas y la presencia de un patrón regional de comercio. No obstante lo anterior, algunos países se diferencian de este comportamiento como es el caso de los exportadores del Cono Sur que acceden a mercados como Rusia, China, Hong Kong y Angola, o de Estados Unidos y Australia. Al comparar la situación entre los países del Mercosur, se obtiene como resultado por un lado, un desigual comportamiento de Argentina respecto de sus socios comerciales y por otro, la relevancia que adquirieron ciertos destinos para Brasil, Uruguay y Paraguay.

Palabras Clave: Comercio internacional; Mercosur; Alimentos.

\footnotetext{
* Escuela Argentina de Negocios (EAN), Argentina.

Contacto: carlosdanielalonso@yahoo.com.ar

** Escuela Argentina de Negocios (EAN), Argentina.

Contacto: carolina.szpak@ean.edu.ar

1 Este artículo se enmarca en la investigación denominada "Mercado de carne vacuna: países exportadores y grandes jugadores privados" Ilevado adelante en la Escuela Argentina de Negocios (EAN), Instituto Universitario, ente financiador del proyecto.
} 


\title{
INTERNATIONAL MARKET OF BEEF: RECENT EVOLUTION OF COMMERCIAL FLOWS AND THE SITUATION OF ARGENTINA
}

\begin{abstract}
This article details the world trade of beef in the period 2006-2015. The analysis of trade flows allows to identify the existence of important players at the country level, certain market concentration both from supply and demand in all the tariff positions involved and the presence of a regional pattern of trade. Notwithstanding the foregoing, some countries differ from this behavior, as is the case of Southern Cone exporters that access markets such as Russia, China, Hong Kong and Angola, or the United States and Australia. When comparing the situation among the Mercosur countries, it is obtained on the one hand, an unequal behavior of Argentina with respect to its commercial partners and on the other hand, the relevance acquired by certain destinations for Brazil, Uruguay and Paraguay.
\end{abstract}

Keywords: International trade; Mercosur; Food.

Original recibido el 17/09/2018

Aceptado para su publicación el 21/01/2020 


\section{Introducción}

El mercado de carne bovina es históricamente significativo para la economía argentina. Desde hace más de una centuria, con la aparición de técnicas de frío para la conservación de los productos, este país comenzó a posicionarse en el comercio internacional con productos reconocidos por las principales plazas del mercado mundial. Actualmente cuenta con un estado sanitario positivo y reconocida calidad de carne debido, entre otros aspectos, a la evolución lograda en genética (Luchetti, 2011).

La inserción externa tuvo un comportamiento dispar en algunos períodos, usualmente atribuido a acciones de gobierno y a la consideración del sector externo como espacio remanente para la colocación de saldos exportables (De las Carreras, 2005; Luchetti, 2011; CIECTI [Centro Interdisciplinario de Estudios en Ciencia, Tecnología e Innovación], 2012 y Ministerio de Hacienda, 2018).

En un trabajo realizado por Bianchi y Szpak (2015) se analizó el comercio internacional de productos agropecuarios de los países del Mercosur (Argentina, Brasil, Paraguay y Uruguay) entre los años 2006 y $2013^{2}$. En dicho relevamiento se detectó la importancia de los productos cárnicos en la canasta exportadora agroindustrial. En el período analizado las exportaciones agroindustriales de Argentina representaron en promedio el $51 \%$ de las exportaciones totales, habiéndose detectado una gran concentración exportadora en un número acotado de cadenas de valor y dentro de ellas, un número reducido de productos. De este modo, siete cadenas de producción representaron el $75 \%$ de exportaciones agroindustriales argentinas y casi el $40 \%$ de sus exportaciones totales.

Particularmente, en el caso de la carne vacuna, las exportaciones de estos productos concentraron un $5 \%$ del total agroindustrial y un $2 \%$ del total de las exportaciones argentinas. Cabe señalar que dentro del comercio agroindustrial son la cuarta cadena de valor en importancia, por detrás de la cadena de valor de la soja ( $46 \%$ de las exportaciones agroindustriales), maíz (10\%) y trigo (6\%).

A su vez, al analizar con mayor detalle dentro del conjunto de carne vacuna, los productos de mayor relevancia fueron la carne refrigerada con el $2 \%$ del total agroindustrial y la congelada con un $1 \%$ adicional.

El objetivo del presente artículo es analizar el flujo de comercio mundial y su concentración; así como identificar el rol de Argentina en comparación con los restantes países del Mercosur durante el período 2006-2015.

\section{Metodología}

En el presente trabajo se realiza un análisis mixto, en el cual se describe el mercado mundial de carne bovina en función del análisis de datos primarios de montos de exportaciones e importaciones a nivel país. Dicha información se obtuvo a partir de la desagregación del comercio por posición arancelaria a seis dígitos, para ello se utilizaron fuentes como ser: la base de datos Comtrade de las Naciones Unidas

2 Para ese análisis se utilizó la definición usual de "agroalimentos" o "productos agroindindustriales", que son aquellos productos contemplados en los primeros 24 capítulos del Sistema Armonizado de Designación y Codificación de Mercancías (SA). La fuente de información utilizada fue la base de datos Comtrade de las Naciones Unidas a nivel de "partida", esto es, cuatro dígitos del SA. 
$(\mathrm{UN})^{3}$ y la base de la Organización Mundial del Comercio (OMC) ${ }^{4}$. Las posiciones arancelarias que se consideraron fueron:

a) Carne fresca y refrigerada: 020110, 020120 y 020130.

b) Carne congelada: 020210, 020220 y 020230.

c) Despojos comestibles de animales: 020610, 020621, 020622 y 020629.

d) Tripas, vejigas y estómagos de animales: 050400 .

e) Las demás preparaciones y conservas de carne y despojos: 160250 y 160290 .

Por otra parte, a partir de los datos de comercio se detectan las siguientes variables:

a) Concentración de oferta a nivel país.

b) Concentración de demanda a nivel país.

En base a estas, se sugiere el desarrollo de un índice de aglomeración de destinos de exportación para cada mercado de origen.

El índice de aglomeración de destinos es el número de destinos que concentran cierto porcentaje de exportación de un origen respecto de los destinos totales a los que accede dicho país de origen. En este caso se obtiene el índice de aglomeración de destinos al $5 \%$, es decir, el número de destinos que adquieren al menos el $5 \%$ de las exportaciones de un país divido el número de destinos totales al que accede dicho origen. Cuanto más bajo sea el resultado que arroje este indicador, menor cantidad de destinos concentrarán un gran porcentaje de las exportaciones de un origen determinado. Este resultado puede estar dado por un muy reducido numerador respecto del denominador, es decir, un pequeño número de mercados que adquieren gran cantidad de las exportaciones de un origen, o por un alto denominador, es decir, un gran número de destinos totales

En la medición de la concentración de la oferta y demanda se evidenciaron los principales países exportadores e importadores que mantuvieron una participación en el mercado de al menos el 5\% en los años 2013-2015.

Finalmente, se compararon las participaciones de los distintos países del Mercosur en el mercado mundial de carne bovina y su evolución en el período 2006-2015. Se elige la comparación entre estos cuatro países (Argentina, Brasil, Paraguay y Uruguay) por dos aspectos esenciales que los vuelven asimilables pese a las diferencias de envergadura y tradición exportadora cárnica. El primero se refiere al acceso comercial, en términos formales de acuerdos preferenciales, que mantienen con terceros mercados por ser parte del mismo bloque económico. El segundo aspecto refiere a que los cuatro países comparten agentes económicos participantes de las cadenas de valor respectivas, aspecto principalmente dado por las inversiones cruzadas que han realizado distintos grupos económicos brasileños en el período reciente (Bianco, Moldovan y Porta, 2008; Bianchi y Szpak, 2015). Estos grupos mantienen estrategias coordinadas para los cuatro países no sólo proveyendo a mercados domésticos, sino aprovisionándose desde el Cono Sur para luego distribuir los productos en terceros mercados. El tercer aspecto es el limitado ejercicio de oferta que pueden hacer en la región, dado que gran parte de la región es proveedora de carne vacuna, generando la necesidad de desarrollar mercados

3 https://comtrade.un.org

4 https://www.wto.org/spanish/res_s/statis_s/merch_trade_stat_s.htm 
relevantes por fuera de la cercanía geográfica.

\section{Evolución reciente del mercado de carne bovina}

El mercado internacional de carne bovina presenta un gran dinamismo, con participantes destacados a lo largo de todos los continentes y con productos signados por diferentes calidades (IPCVA [Instituto de la Promoción de la Carne Vacuna Argentina], 2014). En las últimas décadas, se produjeron cambios en relación a las condiciones climáticas, disponibilidad de recursos naturales, incremento en los precios de insumos alimenticios del ganado, modificaciones sanitarias en la producción y cambios en las preferencias de los consumidores. Esto último principalmente ha originado el aumento del ingreso per cápita e incremento poblacional de ciertos países que condujeron a un aumento de demanda (Errecart, 2015).

Según datos del Departamento de Agricultura de Estados Unidos ${ }^{5}$ (USDA, según sus siglas en inglés), el consumo mundial de carne vacuna llegó en 2015 a 56,4 millones de toneladas, un nivel similar al de 2011. La producción de carne para ese mismo año alcanzó los 58,4 millones de toneladas.

Dentro de los países productores, se destacan Estados Unidos que concentró el $18,5 \%$ de la producción mundial, seguido por Brasil $(16,1 \%)$, la Unión Europea (UE, $13,1 \%)$, China $(11,5 \%)$ e India $(7,0 \%)$.

En términos de comercio, el volumen a nivel mundial fue 9,5 millones de toneladas en 2006 y alcanzó las 12,5 millones de toneladas aproximadamente en 2015, es decir que sostuvo un crecimiento de punta a punta de un $32 \%$. Paralelamente, en términos de valor, se observa que en 2006 las exportaciones mundiales fueron de USD 30.026 millones, mientras que en 2015 llegaron a los USD 51.730 millones, habiéndose incrementado en estos años un $72 \%$ y por tanto, mostrando el impacto del efecto precio en el monto comercializado a nivel global.

Cuando se analiza la distribución del comercio entre las distintas posiciones arancelarias en 2015 , se observa que en términos de volumen, la carne congelada concentró $45 \%$ del comercio mundial, mientras que el segundo lugar lo ocupó la carne refrigerada (34\%). Los despojos comestibles de animales son el tercer grupo de productos cárnicos comercializados (13\%); luego las tripas, vejigas y estómagos $(9 \%)$ y finalmente, las demás preparaciones y conservas de carne y despojos ( $7 \%$ y $5 \%$ respectivamente). Al detenerse en los dos segmentos más relevantes en términos del monto comercializado, la carne fresca o refrigerada en el año 2015 ocupó un $38 \%$ del mercado; mientras que la congelada, $42 \%$.

\section{Concentración del comercio por posición arancelaria}

\subsection{Carne fresca y refrigerada}

Las posiciones arancelarias contempladas para este análisis son: 020110, carne de animales de la especie bovina, fresca o refrigerada en canales o medias canales; 020120, carne de animales de la especie bovina fresca o refrigerada, los demás cortes (trozos) sin deshuesar y 020130 , carne de animales de la especie bovina fresca o refrigerada, deshuesada. En términos de importancia relativa de las posiciones arancelarias dentro de la carne fresca y refrigerada, la posición 020110 concentró

5 https://www.usda.gov 
en el año 2015 el $11,5 \%$ de las exportaciones de este mercado; la 020120, el $23 \%$ y la 020130 es la que presentó la mayor participación del segmento con un $65,5 \%$.

Cabe señalar que Argentina no generó exportaciones entre 2013 y 2015 de la posición arancelaria 020110 y en la 020120, apenas alcanzó una participación promedio del $0,0007 \%$, equivalente a USD 34.000 . En cambio, en la posición arancelaria 020130 , en donde los precios se incrementaron un 3,5\% promedio anual, Argentina logró una participación de mercado promedio del 4,2\% (USD 609 millones aproximadamente), aunque este comportamiento fue descendente en el tiempo (casi un pp. en tres años), es decir, no pudo acompañar sostenidamente el crecimiento del segmento. Según los datos analizados, la concentración del flujo de comercio en las dos primeras posiciones arancelarias -020110 y 020120 - se produce principalmente a nivel intraregional. Es decir que se observan tres bloques regionales que comercian entre sí: el de los países de la UE (Unión Europea) por un lado, el de la ex-URSS (Unión de Repúblicas Socialistas Soviéticas) por otro, y finalmente, el del bloque del NAFTA (Tratado de Libre Comercio de América del Norte). En cuanto a la tercera posición arancelaria, la 020130, también se observa un comercio de cercanía geográfica, destacándose el de los países de la UE por un lado, miembros del NAFTA por otro y un intercambio entre Australia con países asiáticos y árabes. En paralelo a este comportamiento, surgen flujos de comercio entre países de distintas regiones como es el caso de Estados Unidos que exporta a Japón y Corea del Sur o desde Australia hacia Estados Unidos. Un dato a destacar es la aparición de países del Mercosur como agentes relevantes en dicho segmento. Brasil logra una participación del 5,4\% de la oferta global y un $30 \%$ de sus exportaciones se destinan a Chile, luego también logra insertar sus productos en distintos países de la UE y árabes. Argentina por su parte, ocupa el séptimo lugar con un $4,2 \%$ del mercado. Los principales destinos son Alemania $(40 \%)$ y Chile $(20 \%)$. Es decir que si bien hay una cuota de comercio dada por la cercanía, también se logra traspasar este factor.

Un aspecto adicional a la relevancia geográfica en gran parte del comercio es la concentración de un alto porcentaje de las ventas en un número reducido de destinos, respecto del total. En la posición arancelaria 020110, todos los países exportadores colocan más del $80 \%$ de sus exportaciones en menos de cinco países compradores, pese a que algunos orígenes como los Países Bajos tienen una gran diversificación de mercados. La posición 020120 muestra nuevamente que todos los orígenes concentran un gran porcentaje de sus exportaciones (superior al $80 \%$ ) en un número reducido de destinos. Es destacable el rol de los Países Bajos que concentra en seis mercados el 82\%, habiendo accedido a 149 destinos (índice de aglomeración de destinos del 4\%). En la posición 020130 se observa un comportamiento similar a las posiciones arancelarias anteriores, siendo nuevamente los Países Bajos el origen con mayor diversificación y concentración de destinos relevantes.

\subsection{Carne congelada}

Las posiciones arancelarias consideradas para este análisis son: 020210, carne de animales de la especie bovina congelada, en canales o medias canales; 020220, carne de animales de la especie bovina congelada, los demás cortes (trozos) sin deshuesar y 020230, carne de animales de la especie bovina congelada, 
deshuesada. Dentro de la carne congelada, la cual ocupó cerca del $40 \%$ de las ventas de carne vacuna en 2015, la posición arancelaria 020230 concentró el 93\% del valor comercializado de ese año. La posición 020210 tuvo una participación cercana al $1,5 \%$ de la carne congelada en 2015, mientras que la 020220 alcanzó un $5,5 \%$ aproximadamente.

Argentina no tuvo participación de mercado alguna en el segmento de la posición arancelaria 020210 entre 2013 y 2015, aunque sí en los dos restantes. Su cuota de mercado de la posición arancelaria 020220 se redujo fuertemente en estos años, pasando del $1,2 \%$ al $0,1 \%$. En cambio, en la posición arancelaria 020230 , la participación se mantuvo estable en el período, oscilando entre el 1,6\% y el 1,7\%. Es decir que Argentina logró mantener su inserción en el segmento de carne congelada de mayor relevancia y el cual tuvo un comportamiento atractivo tanto desde el punto de vista de las cantidades como del precio. De esta forma creció al ritmo que lo hizo la oferta global y pudo colocar sus productos a un ritmo comparable con el resto de los oferentes.

La oferta de carne congelada, particularmente en la posición 020230 está dominada por Brasil, India y Australia que concentraron cerca del $20 \%$ del mercado cada uno. Luego, Estados Unidos y Nueva Zelanda alcanzaron menos del $10 \%$ cada uno. En cuanto a los principales destinos de exportación, Brasil presenta una alta diversificación de sus mercados relevantes que incluye: Rusia, Hong Kong, Venezuela, países árabes como Egipto e Irán e incluso, accede a la UE a través de Italia. Por su parte, India logra colocar sus productos con cierto patrón regional, dado que el principal destino de exportación es Vietnam (40\%) y luego Malasia y Egipto con $10 \%$ cada uno. En el caso de Australia y Nueva Zelanda, ambos países aprovechan la cercanía geográfica en el desarrollo de su comercio, además de Estados Unidos. Finalmente, el caso de este último país, en su rol de oferente logra un intercambio dentro del NAFTA y con países específicos por fuera de la región, con los cuales mantiene vínculos comerciales en gran parte de la carne vacuna en general (Japón, Hong Kong y Corea del Sur del Sur). Respecto de las otras dos posiciones arancelarias, la 020210 y 020220 , en todos los casos se observa un componente regional. En la 020210 comercio intra-UE, entre países ex-URSS y entre Pakistán y países árabes. En la posición 020220, aparece nuevamente el comercio intra-UE, Australia y países asiáticos y, saltando el patrón de cercanía geográfica, Estados Unidos exporta a Corea del Sur y Hong Kong.

En la posición arancelaria 020210 todos los orígenes mantienen una escasa diversificación de mercados y una elevada concentración, siendo que con seis o menos destinos concentran más del $87 \%$ del mercado. Las exportaciones de la posición 020220 muestran también una elevada concentración dado que como máximo el $13 \%$ de los destinos capturan más del $87 \%$ de las exportaciones de cada país de origen. En el caso de Estados Unidos, sólo dos destinos, Corea del Sur y Hong Kong, adquieren casi el $90 \%$ de sus exportaciones. La posición arancelaria 020230 da cuenta de un comercio en donde Brasil es el origen que tiene una mayor concentración de destinos dado que seis de los 81 mercados a los que accede, capturan el $83 \%$ de sus exportaciones. En todos los casos un número reducido de 
mercados concentra más del $80 \%$ de las exportaciones.

\subsection{Despojos comestible de animales}

Las posiciones arancelarias consideradas para este análisis son: 020610 , despojos de la especie bovina frescos y refrigerados; 020621, lenguas; 020622, hígados y 020629, los demás. Los despojos comestibles de animales ocuparon el $7 \%$ de las exportaciones del mercado de carne vacuno en 2015. El 55\% de las exportaciones globales de este tipo de carne en 2015 correspondió a la posición arancelaria 020629. La segunda posición en orden de importancia (26\% de las ventas en el rubro despojos de animales) fue la 020610.

Argentina mantiene una participación interesante dentro de este mercado. La posición arancelaria de la que menos participa a nivel mundial es en la 020610 con un $0,02 \%$ promedio entre 2013 y 2015 . En cambio, en la posición 020621 alcanzó un $6,5 \%$ de cuota promedio de mercado (USD 22 millones aproximadamente), ocupando el sexto lugar en el ranking mundial. En la posición 020622 Argentina tuvo una participación promedio de mercado del 10\% (USD 28,5 millones), alcanzando el tercer puesto entre los oferentes globales. En la 020629, una de las posiciones más dinámicas desde el punto de vista de las cantidades, el país pudo capturar casi el 5\% (USD 97 millones aproximadamente), ocupando el octavo lugar en el ranking mundial.

Respecto de los principales países jugadores de este rubro, en la posición arancelaria 020629, la más relevante en términos de participación de ventas $(55 \%)$, los principales oferentes son Australia, Brasil y Estados Unidos, cuyas participaciones individuales oscilaron entre el $16 \%$ y $13,5 \%$. Australia y Estados Unidos mantuvieron como principales destinos a países regionalmente cercanos. México adquirió cerca del $45 \%$ de las exportaciones norteamericanas y los principales demandantes de Australia fueron Corea del Sur, Hong Kong, Japón y China. Brasil, al igual que en otros segmentos del mercado de carne vacuna, logró posicionarse en mercados lejanos, aunque con ventas fuertemente concentradas dado que Hong Kong adquiere cerca del $80 \%$ de sus productos. Hong Kong también participa desde la oferta. Tanto para Hong Kong como para India, su principal comprador es Vietnam, país cercano geográficamente. La segunda posición arancelaria en orden de importancia es la 020610 y mantiene un comportamiento similar a otras posiciones. Por un lado se produce un fuerte intercambio entre países de la UE. En paralelo, las exportaciones de Canadá son adquiridas en más del $80 \%$ por los dos restantes socios del NAFTA. Finalmente, en el caso de Australia, Japón concentró el $75 \%$ de sus ventas externas entre 2013 y 2015. En la posición arancelaria 020621 el principal exportador es Estados Unidos con alrededor del $30 \%$ de este mercado. Luego, siguen Australia con cerca del $15 \%$. Ambos países destinan sus ventas externas mayoritariamente a Japón. Brasil también tiene una participación aproximada del 15\% de mercado, siendo sus dos destinos principales Rusia y Hong-Kong, los cuales capturan cerca del $35 \%$ de sus ventas cada uno. Como se vio en otros segmentos, Brasil logra colocar sus productos en los mercados mencionados, aunque en este caso, también

alcanzan relevancia destinos como Israel y Azerbaiján, entre otros. Argentina mantuvo una participación similar a la de Nueva Zelanda y Canadá (6,5\%). Mientras 
que Argentina coloca sus productos en Rusia ( $84 \%$ de sus ventas externas), estrategia similar a Brasil; Nueva Zelanda lo hace en Japón y Canadá. Finalmente, respecto de la posición arancelaria 020622, no se observa claramente un patrón de comercio según cercanía geográfica. Estados Unidos captura algo más del 40\% de este segmento, siendo su principal comprador Egipto (86\% entre 2013 y 2015). Australia y Argentina mantienen participaciones de mercado similares y del orden del $10 \%$ cada una. El primer país destina más del $40 \%$ de sus ventas a Egipto y un $20 \%$ a Sudáfrica; mientras que el socio comercial más significativo de Argentina es nuevamente Rusia (88\%), como ocurre con otras posiciones arancelarias.

En la posición 020610 la mayor concentración se presenta en Estados Unidos, Australia y Países Bajos en donde cerca del 5\% de los mercados a los que estos países acceden capturan más del $80 \%$ de las exportaciones de cada origen. Por otro lado, en la posición 020621 se presenta una escasa diversificación de mercados para todos los orígenes relevantes (con ventas superiores al $5 \%$ del mercado). En todos los casos, cuatro o menos destinos concentran más del $75 \%$. En cuanto a la posición arancelaria 020622, el principal oferente mundial es Estados Unidos y coloca el $86 \%$ de sus exportaciones en un solo destino que es Egipto. Argentina, es el segundo oferente con mayor concentración debido al escaso desarrollo relativo de mercados (13 mercados). Australia concentra en el $9 \%$ de sus mercados el $76 \%$ de sus exportaciones. Finalmente, en la posición arancelaria 020629 se observa que Brasil es el origen con mayor concentración dado que en Hong Kong coloca el 80\% de sus exportaciones.

\subsection{Tripas, vejigas y estómagos de animales}

Todo el comercio de tripas, vejigas y estómagos de animales correspondientes al mercado de carne vacuna se concentran en una sola posición arancelaria (050400). Por el bajo nivel de desagregación con la que se dispone, esta posición encierra las tripas y demás de distintos tipos de animal, aunque el dominante sea el bovino.

Argentina tiene una participación en este segmento cercana al 1\% entre 2013 y 2015, con un monto promedio de ventas de USD 41 millones anuales.

En cuanto a los principales oferentes mundiales, China concentra cerca del $20 \%$ del mercado, mientas que Alemania, Brasil y Estados Unidos participan en un $10 \%$ cada uno. El análisis de la colocación de productos señala que China colocó alrededor del $20 \%$ de sus ventas en Alemania, mientras que Estados Unidos, Japón, Tailandia y Brasil adquieren el 10\% de sus exportaciones cada uno. Alemania, también actúa como oferente, siendo Francia y Polonia sus principales compradores (15\% cada uno), es decir que pese a que sus principales compradores son del entorno intracomunitario, también surgen demandantes de orígenes asiáticos como Hong Kong y China. Brasil, al igual que con otros productos del mercado de carne vacuna, logra colocar cerca del $70 \%$ de sus exportaciones en Hong Kong, aunque también vende a Rusia, ciertos países de la UE y Paraguay. Finalmente, Estados Unidos coloca sus productos mayoritariamente en México y China (35\% cada uno).

Brasil es el oferente con mayor concentración dado que en el $2 \%$ de sus destinos, coloca el $67 \%$ de sus exportaciones. El porcentaje acumulado de exportaciones de cualquier origen en destinos relevantes no supera el $57 \%-76 \%$, a diferencia de la 
mayoría de posiciones arancelarias analizadas en donde dicho porcentaje suele ser mayor. Esto implica que los países oferentes venden a diversos mercados pero con participaciones menores al $5 \%$ mostrando un interesante ejercicio de diversificación exportadora.

\subsection{Las demás preparaciones y conservas de carne o sangre}

Las posiciones arancelarias consideradas para este análisis son: 160250, las demás preparaciones y conservas de carne y sangre de la especie bovina y 160290, las demás, incluidas cualquier preparación de sangre de cualquier animal.

Argentina mantuvo una participación promedio en la posición arancelaria 160250 cercana al 3,4\%, con exportaciones de alrededor de USD 83 millones promedio anuales. En cuanto a la posición arancelaria 160290, su rol fue mucho menos relevante, participando con un $0,13 \%$, es decir con exportaciones promedio cercanas a los USD 380 mil.

Los principales jugadores del mercado difieren entre las posiciones arancelarias involucradas. En la 160250 Brasil ocupa el 25\% del mercado aproximadamente, mientras que Estados Unidos, Irlanda y Alemania participan en un $10 \%$ cada uno. Argentina ocupa el octavo lugar con un 3,4\% del mercado mundial. Los países europeos comercian principalmente a nivel intracomunitario, Estados Unidos en el NAFTA (Canadá con un $70 \%$ ) y Hong Kong (20\%), y Brasil logra insertar sus productos en Estados Unidos (50\% aproximadamente) y ciertos países europeos (se destaca Bélgica con el 20\%). En cuanto a la posición arancelaria 160290, nuevamente se observa el comercio intracomunitario en los países de la UE (Irlanda, Alemania y Francia son oferentes destacados), China coloca cerca del $100 \%$ de sus exportaciones en Estados Unidos y México, y Emiratos Árabes exporta sus productos a distintos países de la región (Arabia Saudita, Kuwait, Omán, Irak, Qatar y Jordania, entre otros).

En el comercio de la posición arancelaria 160250 tanto Brasil como Estados Unidos son orígenes en donde cerca del $3 \%$ de sus mercados capturan entre el $70 \%$ y $90 \%$ de sus exportaciones, respectivamente. El porcentaje de exportaciones acumuladas en dichos destinos muestra una mayor vulnerabilidad de Estados Unidos, paralelamente a un menor número de mercados desarrollados. Finalmente, en relación a la posición arancelaria 160290, se observa un reducido número de mercados de China. En Irlanda, por su parte aproximadamente el $7 \%$ de sus mercados capturan el $90 \%$ de su comercio.

\subsection{Reflexiones acerca de los flujos comerciales internacionales}

Una vez analizado en detalle el flujo comercial de cada posición arancelaria a seis dígitos en el período 2006-2015, puede observarse la importancia del comercio regional, es decir que gran parte de las operaciones se realizan en entornos con cercanía geográfica. En el caso de la carne vacuna se detectan flujos comerciales en tres grandes áreas: región del norte de América (bloque NAFTA), región europea (UE ampliada y ex-URSS) y región Oceanía con países asiáticos y árabes.

Paralelamente, ciertos países generan un comercio que traspasa este patrón. Los casos destacados son Estados Unidos que logra colocar sus productos en Hong 
Kong, Corea del Sur y Japón, principalmente; también Australia y Nueva Zelanda que intercambia con países del NAFTA; y por último, los países del Cono Sur que logran ingresar fuertemente en Rusia y Hong Kong y en determinadas posiciones acceden al mercado europeo $u$ otros asiáticos y árabes.

Otra característica común es la elevada concentración tanto en la oferta y demanda. Si bien pueden existir numerosos países oferentes y demandantes, el núcleo del comercio se desarrolla en un número acotado de jugadores. El índice de aglomeración muestra que cada país oferente relevante (con más del $5 \%$ de la oferta mundial) logra exportar mayoritariamente a un número reducido de mercados. Es decir que sin importar el número de destinos totales al que accede cada origen, sólo unos pocos mercados se transforman en relevantes para los distintos oferentes.

Este comportamiento permite señalar distintos aspectos. El primero es que podría existir cierto grado de vulnerabilidad para los oferentes dado que de cerrarse un mercado de destino, se tornaría necesario generar alternativas significativas de manera ágil para minimizar las consecuencias en el sector exportador. En paralelo, una restricción de la oferta en uno de los jugadores relevantes impactaría en los precios de mercado internacional.

Otro aspecto es que junto a estos pocos destinos significativos, hay un conjunto de países con potencialidad de incrementar la participación de mercado gracias a un crecimiento dinámico dado por aumentos rápidos de la población, del ingreso y de la urbanización. Distintos autores como Llach (2012) y Bianchi y Szpak (2015) indagan en la existencia de mercados potenciales para distintos productos de la canasta exportadora argentina. La posibilidad de avanzar de manera agregada hacia mercados potenciales requeriría de un gran esfuerzo no sólo del sector privado, sino también del sector público en relación a generar mejores condiciones de acceso y desarrollo de herramientas financieras y contractuales adecuadas, entre otros aspectos.

Finalmente, la elevada concentración de mercados relevantes facilita el objetivo en las negociaciones comerciales y la posibilidad de resentar propuestas para un grupo acotado de oferentes que permitan asegurar el abastecimiento de alimentos a un porcentaje importante de la población mundial en un contexto de inseguridad alimentaria (Bianchi y Piñeiro, 2017).

\section{Inserción reciente de Argentina y los restantes países del Mercosur: aspectos comparativos 2006-2015}

En este apartado se analiza el dinamismo del flujo comercial que mantuvieron los distintos países del Mercosur de manera comparada.

Para analizar la evolución del flujo comercial se consideran los segmentos de mercado más dinámicos y las posiciones arancelarias en las que Argentina tiene cierta participación de mercado para luego comparar el comportamiento de este país con los restantes del Mercosur (Tabla 1). 
Tabla 1. Dinamismo de las exportaciones mundiales de carne vacuna por posición arancelaria. Participación de mercado de los países del Mercosur (en porcentaje).

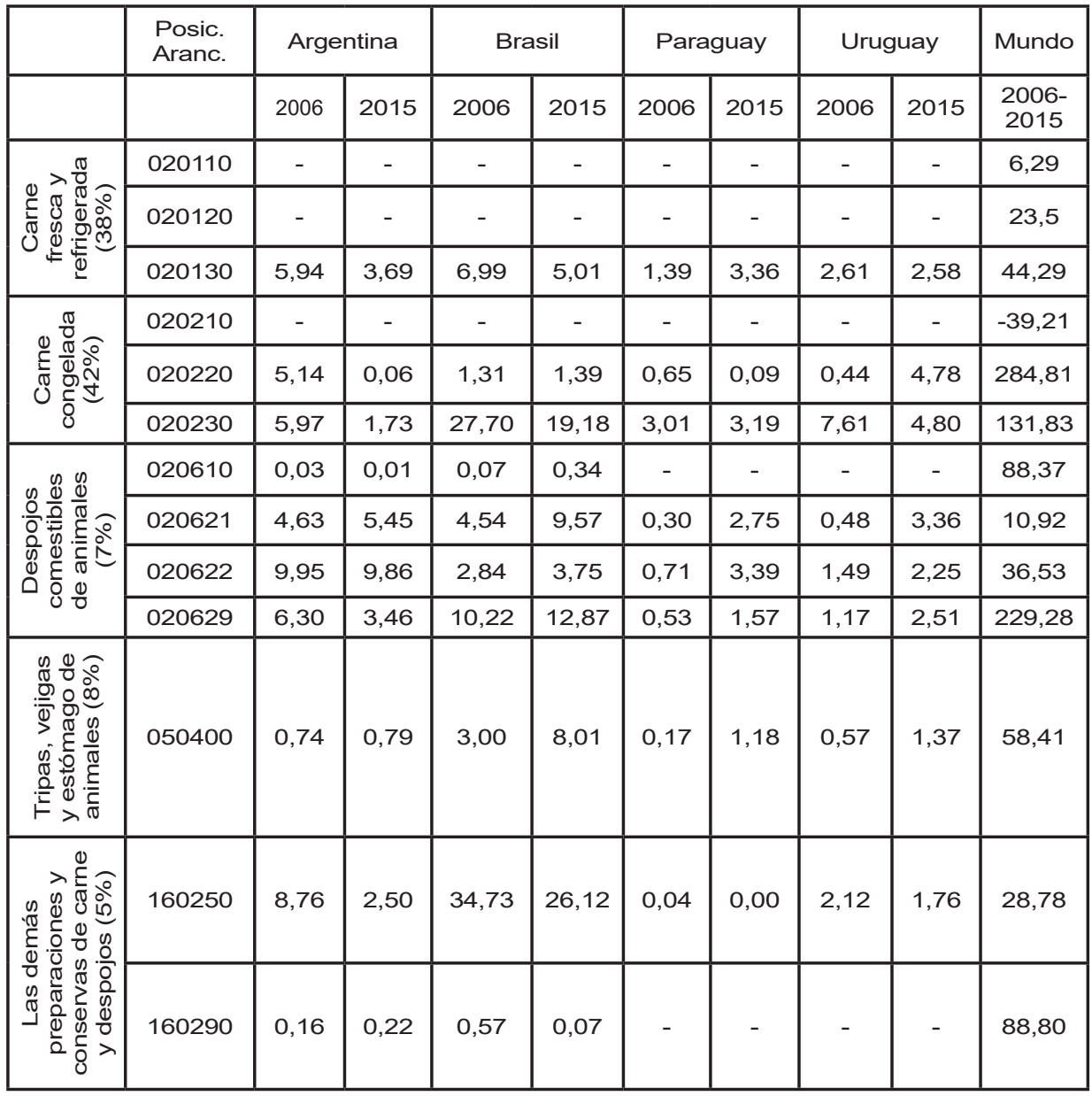

Fuente: Elaboración propia con base en UN Comtrade.

En función de los datos de la Tabla 1 puede señalarse lo siguiente:

a) Argentina pierde cuota de mercado en la carne fresca y refrigerada, al igual que Brasil, aunque este último lo hace en menor cuantía. Paraguay y Uruguay, en cambio, logran incrementar o mantener su participación en el mercado mundial.

b) Argentina también reduce su participación de mercado en la carne congelada. En la posición arancelaria más relevante (020230) todos los países del Mercosur pierden participación de mercado, excepto Paraguay.

c) En el mercado de despojos comestibles el comportamiento de Argentina es diverso, según la posición arancelaria. En la posición arancelaria 020629, más dinámica y relevante por cuantía de comercio, Argentina perdió participación de 
mercado. En las restantes posiciones, en donde incrementó su cuota o se mantuvo estable, obtuvo la performance menos destacada dentro de los países del Mercosur.

d) En el mercado de tripas, estómagos y vejigas de animales Argentina mantuvo su participación de mercado pero todos los restantes países del Mercosur la incrementaron.

e) En el mercado de las demás preparaciones y conservas de carne y despojos, todos los países ven afectada su participación en el período analizado.

En función de estos puntos señalados, resulta conveniente analizar cuáles fueron los mercados que adquirieron mayor relevancia en estos años para los restantes países del Mercosur. Es decir, revisar si los mismos incrementaron su participación de mercado en destinos ya abiertos, o lograron acceder a nuevos mercados.

\subsection{Carne fresca y refrigerada}

En la posición arancelaria 020130 tanto Uruguay como Paraguay ganaron participación de mercado. Uruguay redujo la cantidad de destinos a los que exporta a través del tiempo, pasando de 36 a 26 mercados y, paralelamente, el conjunto de países que captura al menos el $5 \%$ de las exportaciones de este origen acumula mayor porcentaje de las ventas totales.

En cuanto a la estrategia de Paraguay, este país presenta un movimiento doble. Por un lado incrementa la concentración dentro del Cono Sur, y por otro, aumenta levemente el número de destinos totales aunque con participaciones menores al $2 \%$.

Tabla 2. Posición arancelaria 020130. Exportaciones por país.

Uruguay

\begin{tabular}{|c|c|c|c|c|c|}
\hline \multicolumn{2}{|c|}{2006} & \multicolumn{2}{c|}{2010} & \multicolumn{2}{c|}{2015} \\
\hline País & Participación & País & Participación & País & Participación \\
\hline UE & $38 \%$ & UE & $50 \%$ & UE & $62 \%$ \\
\hline Chile & $34 \%$ & Chile & $17 \%$ & Chile & $8 \%$ \\
\hline $\begin{array}{c}\text { Estados } \\
\text { Unidos }\end{array}$ & $12 \%$ & $\begin{array}{c}\text { Estados } \\
\text { Unidos }\end{array}$ & $5 \%$ & $\begin{array}{c}\text { Estados } \\
\text { Unidos }\end{array}$ & $12 \%$ \\
\hline Brasil & $6 \%$ & Brasil & $10 \%$ & Brasil & $6 \%$ \\
\hline- & $39 \%$ & Suiza & $5 \%$ & Suiza & $6 \%$ \\
\hline Total & 36 & $\begin{array}{c}\text { Destinos } \\
\text { totales }\end{array}$ & $35 \%$ & Total & $89 \%$ \\
\hline $\begin{array}{c}\text { Destinos } \\
\text { totales }\end{array}$ & & $\begin{array}{c}\text { Destinos } \\
\text { totales }\end{array}$ & 26 \\
\hline
\end{tabular}

Paraguay

\begin{tabular}{|c|c|c|c|c|c|}
\hline \multicolumn{2}{|c|}{2006} & \multicolumn{2}{c|}{2010} & \multicolumn{2}{c|}{2015} \\
\hline País & Participación & País & Participación & País & Participación \\
\hline Chile & $83 \%$ & Chile & $87 \%$ & Chile & $70 \%$ \\
\hline Brasil & $9 \%$ & Brasil & $6 \%$ & Brasil & $23 \%$ \\
\hline Total & $91 \%$ & Total & $93 \%$ & Total & $93 \%$ \\
\hline $\begin{array}{c}\text { Destinos } \\
\text { totales }\end{array}$ & 16 & $\begin{array}{c}\text { Destinos } \\
\text { totales }\end{array}$ & 21 & $\begin{array}{c}\text { Destinos } \\
\text { totales }\end{array}$ & 22 \\
\hline
\end{tabular}

Fuente: Elaboración propia con base en UN Comtrade. 
Por último, al analizar los principales importadores mundiales, se observa cierta concentración dado que un grupo de países adquieren más del $60 \%$ de las importaciones mundiales de la posición arancelaria 020130. Esto confirma nuevamente que no sólo hay concentración en la oferta, sino también en la demanda. Al conjugar las exportaciones de Uruguay con estos datos, se destaca que este país logra ingresar a mercados relevantes como Estados Unidos, distintos países de la UE y Chile, mientras que Paraguay sólo accede al mercado destacado de la región que es Chile (5\% de las importaciones mundiales).

\subsection{Carne congelada}

En el caso de la carne congelada, Brasil logró mantener su cuota de mercado mundial en el segmento 020220. Esto se hizo con una mayor concentración de sus exportaciones en un reducido número de destinos y en una menor diversificación global de mercados. Uruguay es el origen del Mercosur que gana participación de mercado a nivel global a costa de una gran concentración de sus exportaciones relevantes y un limitado número de mercados al que abastece.

Tabla 3. Posición arancelaria 020220. Exportaciones por país.

Brasil

\begin{tabular}{|c|c|c|c|c|c|}
\hline \multicolumn{2}{|c|}{2006} & \multicolumn{2}{|c|}{2010} & \multicolumn{2}{|c|}{2015} \\
\hline País & Participación & País & Participación & País & Participación \\
\hline Angola & $30 \%$ & Angola & $51 \%$ & Angola & $69 \%$ \\
\hline Rusia & $29 \%$ & Rusia & $21 \%$ & Hong Kong & $22 \%$ \\
\hline $\begin{array}{l}\text { Arabia } \\
\text { Saudita }\end{array}$ & $11 \%$ & $\begin{array}{l}\text { Hong } \\
\text { Kong }\end{array}$ & $16 \%$ & $\begin{array}{c}\text { Emiratos } \\
\text { Árabes }\end{array}$ & $5 \%$ \\
\hline $\begin{array}{c}\text { Emiratos } \\
\text { Árabes }\end{array}$ & $6 \%$ & - & - & - & - \\
\hline Brunei & $6 \%$ & - & - & - & - \\
\hline Total & $81 \%$ & Total & $88 \%$ & Total & $96 \%$ \\
\hline $\begin{array}{c}\text { Destinos } \\
\text { totales }\end{array}$ & 28 & $\begin{array}{c}\text { Destinos } \\
\text { totales }\end{array}$ & 17 & $\begin{array}{c}\text { Destinos } \\
\text { totales }\end{array}$ & 18 \\
\hline
\end{tabular}

Uruguay

\begin{tabular}{|c|c|c|c|c|c|}
\hline \multicolumn{2}{|c|}{2006} & \multicolumn{2}{|c|}{2010} & \multicolumn{2}{|c|}{2015} \\
\hline País & Participación & País & Participación & País & Participación \\
\hline Brasil & $63 \%$ & Brasil & $44 \%$ & China & $98 \%$ \\
\hline Angola & $29 \%$ & China & $24 \%$ & China & $98 \%$ \\
\hline- & - & $\begin{array}{l}\text { Arabia } \\
\text { Saudita }\end{array}$ & $16 \%$ & - & - \\
\hline- & - & $\begin{array}{l}\text { Hong } \\
\text { Kong }\end{array}$ & $8 \%$ & - & - \\
\hline- & - & Angola & $6 \%$ & - & - \\
\hline Total & $92 \%$ & Total & $99 \%$ & Total & $98 \%$ \\
\hline $\begin{array}{c}\text { Destinos } \\
\text { totales }\end{array}$ & 5 & $\begin{array}{c}\text { Destinos } \\
\text { totales }\end{array}$ & 9 & $\begin{array}{l}\text { Destinos } \\
\text { totales }\end{array}$ & 5 \\
\hline
\end{tabular}

Fuente: Elaboración propia con base en UN Comtrade. 
Los principales importadores mundiales se mantienen a lo largo del tiempo y son Corea del Sur con una cuota decreciente y Arabia Saudita con un comportamiento estable. Por su parte Hong Kong adquiere relevancia y China toma un rol destacado en 2015. En el grupo de destinos relevantes, Brasil provee a Arabia Saudita en 2006 y a Hong Kong en 2010, aunque luego toma una alta relevancia Angola que ocupa el puesto número ocho en el ranking mundial de importadores en 2015 con el $2 \%$ de las compras mundiales. Uruguay pasa a exportar a China en los dos últimos años analizados, jugador que cobra importancia a nivel mundial y Paraguay abastece a Angola y a Rusia que ocupa el noveno lugar en el ranking mundial con una participación cercana al $2 \%$.

Por último, en cuanto a la posición 020230, Paraguay es el único país del bloque que logra mantener o incrementar levemente su cuota de mercado. Rusia ocupa un rol dominante entre sus mercados, aunque con una participación que decae en el tiempo En 2015 se observa una menor concentración de destinos ya que logra avanzar sobre mercados asiáticos y diversifica mercados.

Tabla 4. Posición arancelaria 020230. Exportaciones por país.

\begin{tabular}{|c|c|c|c|c|c|}
\hline \multicolumn{2}{|c|}{ Paraguay } & \multicolumn{2}{c|}{2015} \\
\hline País & Participación & País & Participación & País & Participación \\
\hline Rusia & $81 \%$ & Rusia & $59 \%$ & Rusia & $51 \%$ \\
\hline Angola & $6 \%$ & Venezuela & $13 \%$ & Israel & $12 \%$ \\
\hline Israel & $6 \%$ & Israel & $7 \%$ & Kuwait & $6 \%$ \\
\hline- & - & - & - & Vietnam & $5 \%$ \\
\hline Total & $93 \%$ & Total & $79 \%$ & Total & $75 \%$ \\
\hline $\begin{array}{c}\text { Destinos } \\
\text { totales }\end{array}$ & 30 & $\begin{array}{c}\text { Destinos } \\
\text { totales }\end{array}$ & 52 & Destinos & 42 \\
\hline
\end{tabular}

Fuente: Elaboración propia con base en UN Comtrade.

\subsection{Despojos comestibles de animales}

En el caso del mercado de los despojos comestibles de animales, en la posición 020621 todos los países del Mercosur incrementaron su cuota de mercado mundial, inclusive Argentina.

Brasil tuvo un descenso en el número de destinos a través del tiempo, destacándose el creciente rol de Hong Kong y la inestabilidad de Rusia.

En cuanto a Uruguay, los mercados ruso, chino e israelí son los que se mantienen a través del tiempo y los cuales concentran cerca del $100 \%$ de las exportaciones de ese origen, considerando la poca diversificación de destinos alcanzados.

Paraguay, pese a acceder a un mayor número de mercados, concentra su comercio mayoritariamente en Rusia e Israel, con lo cual su participación en el mercado mundial, depende fuertemente de las compras de estos países. 
Tabla 5. Posición arancelaria 020621. Exportaciones por país.

\section{Brasil}

\begin{tabular}{|c|c|c|c|c|c|}
\hline \multicolumn{2}{|c|}{2006} & \multicolumn{2}{c|}{2010} & \multicolumn{2}{c|}{2015} \\
\hline País & Participación & País & Participación & País & Participación \\
\hline Rusia & $38 \%$ & Kazajistán & $43 \%$ & Rusia & $37 \%$ \\
\hline Kazajistán & $15 \%$ & Ucrania & $17 \%$ & Hong Kong & $33 \%$ \\
\hline Francia & $12 \%$ & Hong Kong & $17 \%$ & Israel & $8 \%$ \\
\hline Hong Kong & $8 \%$ & Israel & $9 \%$ & Azerbaijan & $7 \%$ \\
\hline Suiza & $6 \%$ & Moldavia & $7 \%$ & - & - \\
\hline Israel & $6 \%$ & - & - & - & - \\
\hline Total & $84 \%$ & Total & $93 \%$ & Total & $85 \%$ \\
\hline $\begin{array}{c}\text { Destinos } \\
\text { totales }\end{array}$ & 30 & $\begin{array}{c}\text { Destinos } \\
\text { totales }\end{array}$ & 18 & Destinos & 21 \\
\hline
\end{tabular}

\section{Uruguay}

\begin{tabular}{|c|c|c|c|c|c|}
\hline \multicolumn{2}{|c|}{2006} & \multicolumn{2}{c|}{2010} & \multicolumn{2}{c|}{2015} \\
\hline País & Participación & País & Participación & País & Participación \\
\hline Israel & $50 \%$ & Rusia & $88 \%$ & China & $65 \%$ \\
\hline Rusia & $38 \%$ & Israel & $10 \%$ & Israel & $20 \%$ \\
\hline China & $6 \%$ & Total & $99 \%$ & Rusia & $14 \%$ \\
\hline Total & $94 \%$ & Destinos & 3 & $\begin{array}{c}\text { Destinos } \\
\text { totales }\end{array}$ & 4 \\
\hline $\begin{array}{c}\text { Destinos } \\
\text { totales }\end{array}$ & 10 & totales & & & $100 \%$ \\
\hline
\end{tabular}

\section{Paraguay}

\begin{tabular}{|c|c|c|c|c|c|}
\hline \multicolumn{2}{|c|}{2006} & \multicolumn{2}{c|}{2010} & \multicolumn{2}{c|}{2015} \\
\hline País & Participación & País & Participación & País & Participación \\
\hline Israel & $33 \%$ & Rusia & $91 \%$ & Rusia & - \\
\hline Rusia & $25 \%$ & Israel & $8 \%$ & Israel & - \\
\hline Kazajistán & $15 \%$ & - & - & - & - \\
\hline Colombia & $8 \%$ & - & - & - & - \\
\hline Perú & $5 \%$ & - & - & - & - \\
\hline Total & $85 \%$ & Total & $99 \%$ & Total & $96 \%$ \\
\hline $\begin{array}{c}\text { Destinos } \\
\text { totales }\end{array}$ & 13 & $\begin{array}{c}\text { Destinos } \\
\text { totales }\end{array}$ & 9 & $\begin{array}{c}\text { Destinos } \\
\text { totales }\end{array}$ & 10 \\
\hline
\end{tabular}

Fuente: Elaboración propia con base en UN Comtrade.

Los principales importadores de la posición arancelaria 020621 están muy concentrados y se mantienen a lo largo del tiempo, siendo Japón el más relevante con más del $50 \%$ del mercado, luego le siguen México y Rusia. Tanto Brasil, Uruguay como Paraguay acceden al mercado ruso, aunque no a los restantes de manera significativa (al menos el $5 \%$ de las exportaciones). Paraguay es el origen que destina mayor porcentaje de sus exportaciones a dicho destino.

Al analizar la posición arancelaria 020622, se observa que Brasil redujo notoriamente la cantidad de mercados al que accede a través del tiempo. Egipto es el país que 
se mantiene a lo largo de todos los años analizados, incrementando fuertemente su participación sobre el final de la serie y Rusia también surge como un jugador relevante aunque de forma intermitente y descendente.

Tabla 6. Posición arancelaria 020622. Exportaciones por país.

\section{Brasil}

\begin{tabular}{|c|c|c|c|c|c|}
\hline \multicolumn{2}{|c|}{2006} & \multicolumn{2}{|c|}{2010} & \multicolumn{2}{|c|}{2015} \\
\hline País & Participación & País & Participación & País & Participación \\
\hline Egipto & $42 \%$ & Egipto & $40 \%$ & Egipto & $86 \%$ \\
\hline Rusia & $37 \%$ & Kuwait & $17 \%$ & Rusia & $12 \%$ \\
\hline Kazajistán & $10 \%$ & Angola & $12 \%$ & - & - \\
\hline - & - & Libia & $7 \%$ & - & - \\
\hline - & - & $\begin{array}{l}\text { Arabia } \\
\text { Saudita }\end{array}$ & $6 \%$ & - & - \\
\hline - & - & $\begin{array}{c}\text { Emiratos } \\
\text { Árabes }\end{array}$ & $5 \%$ & - & - \\
\hline Total & $89 \%$ & Total & $87 \%$ & Total & $98 \%$ \\
\hline $\begin{array}{c}\text { Destinos } \\
\text { totales }\end{array}$ & 30 & $\begin{array}{c}\text { Destinos } \\
\text { totales }\end{array}$ & 18 & $\begin{array}{c}\text { Destinos } \\
\text { totales }\end{array}$ & 8 \\
\hline
\end{tabular}

\section{Uruguay}

\begin{tabular}{|c|c|c|c|c|c|}
\hline \multicolumn{2}{|c|}{2006} & \multicolumn{2}{c|}{2010} & \multicolumn{2}{c|}{2015} \\
\hline País & Participación & País & Participación & País & Participación \\
\hline Rusia & $53 \%$ & Rusia & $77 \%$ & Rusia & $89 \%$ \\
\hline Brasil & $25 \%$ & $\begin{array}{c}\text { Zonas } \\
\text { Francas }\end{array}$ & $11 \%$ & - & - \\
\hline Israel & $9 \%$ & Brasil & $10 \%$ & - & - \\
\hline $\begin{array}{c}\text { Zonas } \\
\text { Francas }\end{array}$ & $6 \%$ & - & - & - & - \\
\hline Total & $93 \%$ & Total & $98 \%$ & Total & $89 \%$ \\
\hline $\begin{array}{c}\text { Destinos } \\
\text { totales }\end{array}$ & 13 & $\begin{array}{c}\text { Destinos } \\
\text { totales }\end{array}$ & 6 & $\begin{array}{c}\text { Destinos } \\
\text { totales }\end{array}$ & 7 \\
\hline
\end{tabular}

\section{Paraguay}

\begin{tabular}{|c|c|c|c|c|c|}
\hline \multicolumn{2}{|c|}{2006} & \multicolumn{2}{c|}{2010} & \multicolumn{2}{c|}{2015} \\
\hline País & Participación & País & Participación & País & Participación \\
\hline Perú & $36 \%$ & Rusia & $81 \%$ & Rusia & $95 \%$ \\
\hline Colombia & $27 \%$ & Colombia & $12 \%$ & - & - \\
\hline Rusia & $12 \%$ & - & - & - & - \\
\hline Israel & $6 \%$ & - & - & - & - \\
\hline Total & $81 \%$ & Total & $93 \%$ & Total & $95 \%$ \\
\hline $\begin{array}{c}\text { Destinos } \\
\text { totales }\end{array}$ & 17 & $\begin{array}{c}\text { Destinos } \\
\text { totales }\end{array}$ & 15 & $\begin{array}{c}\text { Destinos } \\
\text { totales }\end{array}$ & 12 \\
\hline
\end{tabular}

Fuente: Elaboración propia con base en UN Comtrade. 
Uruguay también reduce los mercados totales a los que accede, siendo Rusia su destino más significativo.

En el caso de Paraguay, Rusia también es su mayor comprador, pasando de adquirir un $12 \%$ en 2006, a capturar un $95 \%$ en 2015 .

En este segmento se observa una elevada concentración de destinos relevantes, siendo Egipto y Rusia los dos principales demandantes y con cuotas muy por debajo (menores al 4\%) el resto de los compradores. Para Brasil estos dos destinos son significativos, al punto de concentrar la mayor parte de sus exportaciones de 2015 en ambos (92\%). Uruguay y Paraguay acceden a Rusia, también adquiriendo cerca del $90 \%$ de las exportaciones de 2015 para los dos países.

En cuanto a la posición arancelaria 020629, la cual tuvo el comportamiento más dinámico entre 2006 y 2015, se observa que Brasil mantuvo como principal y creciente socio comercial a Hong Kong, el cual concentró un $80 \%$ de las ventas de ese destino.

En el caso de Uruguay, China adquiere importancia a través del tiempo en desmedro de otros destinos.

Paraguay muestra que Rusia y Hong Kong ganan importancia en sus destinos de exportación, mientras que Vietnam, Gabón y Perú continúan en el grupo relevante aunque con participaciones cambiantes según el año. En paralelo se logra una mayor diversificación de destinos.

Entre los principales importadores se destacan por su participación en el tiempo Hong Kong con una cuota de mercado creciente, México que perdió participación, Corea del Sur y Estados Unidos. Japón, pese a que en los dos últimos años no se encuentre entre los que capturan al menos el $5 \%$ del mercado, logra cerca del $4 \%$ del mismo. Hong Kong es un destino de absoluta relevancia para Brasil, al punto que termina concentrando en 2015 el $80 \%$ de sus exportaciones. En Paraguay este mercado adquiere importancia a partir de 2010 , aunque con una participación mucho menor ( $7 \%$ en 2010 y 19\% en 2015). Por su parte para Uruguay fue importante en 2006 y 2010, aunque China toma preeminencia en 2015. Los restantes importadores no son significativos para estos tres países del Mercosur en los años analizados. 
Tabla 7. Posición arancelaria 020629. Exportaciones por país.

Brasil

\begin{tabular}{|c|c|c|c|c|c|}
\hline \multicolumn{2}{|c|}{2006} & \multicolumn{2}{c|}{2010} & \multicolumn{2}{c|}{2015} \\
\hline País & Participación & País & Participación & País & Participación \\
\hline Hong Kong & $69 \%$ & Hong Kong & $83 \%$ & Hong Kong & $80 \%$ \\
\hline Rusia & $6 \%$ & Perú & $5 \%$ & Hong Kong & $80 \%$ \\
\hline $\begin{array}{c}\text { Costa de } \\
\text { Marfil }\end{array}$ & $5 \%$ & - & - & - & - \\
\hline Total & $81 \%$ & Total & $89 \%$ & Total & $80 \%$ \\
\hline $\begin{array}{c}\text { Destinos } \\
\text { totales }\end{array}$ & 54 & $\begin{array}{c}\text { Destinos } \\
\text { totales }\end{array}$ & 45 & $\begin{array}{c}\text { Destinos } \\
\text { totales }\end{array}$ & 50 \\
\hline
\end{tabular}

\section{Uruguay}

\begin{tabular}{|c|c|c|c|c|c|}
\hline \multicolumn{2}{|c|}{2006} & \multicolumn{2}{c|}{2010} & \multicolumn{2}{c|}{2015} \\
\hline País & Participación & País & Participación & País & Participación \\
\hline Hong Kong & $27 \%$ & Hong Kong & $48 \%$ & China & $84 \%$ \\
\hline Gabón & $23 \%$ & China & $17 \%$ & - & - \\
\hline China & $14 \%$ & Rusia & $7 \%$ & - & - \\
\hline Israel & $8 \%$ & Gabón & $6 \%$ & - & - \\
\hline Perú & $8 \%$ & - & - & - & $84 \%$ \\
\hline Total & $79 \%$ & Total & $78 \%$ & Total & 18 \\
\hline $\begin{array}{c}\text { Destinos } \\
\text { totales }\end{array}$ & 25 & $\begin{array}{c}\text { Destinos } \\
\text { totales }\end{array}$ & 32 & Destinos & totales \\
\hline
\end{tabular}

\section{Paraguay}

\begin{tabular}{|c|c|c|c|c|c|}
\hline \multicolumn{2}{|c|}{2006} & \multicolumn{2}{|c|}{2010} & \multicolumn{2}{|c|}{2015} \\
\hline País & Participación & País & Participación & País & Participación \\
\hline Perú & $19 \%$ & Rusia & $32 \%$ & Rusia & $22 \%$ \\
\hline Angola & $19 \%$ & Vietnam & $18 \%$ & Hong Kong & $19 \%$ \\
\hline Gabón & $16 \%$ & Gabón & $10 \%$ & Gabón & $16 \%$ \\
\hline Vietnam & $15 \%$ & Perú & $9 \%$ & Vietnam & $13 \%$ \\
\hline Ghana & $6 \%$ & Hong Kong & $7 \%$ & Perú & $7 \%$ \\
\hline- & - & China & $6 \%$ & Serbia & $5 \%$ \\
\hline- & - & Angola & $5 \%$ & - & - \\
\hline Total & $75 \%$ & Total & $87 \%$ & Total & $82 \%$ \\
\hline $\begin{array}{c}\text { Destinos } \\
\text { totales }\end{array}$ & 21 & $\begin{array}{c}\text { Destinos } \\
\text { totales }\end{array}$ & 23 & $\begin{array}{c}\text { Destinos } \\
\text { totales }\end{array}$ & 32 \\
\hline
\end{tabular}

Fuente: Elaboración propia con base en UN Comtrade.

\subsection{Tripas, vejigas y estómagos de animales}

Brasil es el país del Mercosur que mayor cuota de mercado logra capturar en el período analizado. En este sentido, se observa un fuerte incremento de destinos entre 2006 y los otros dos períodos. Paralelamente, Hong Kong incrementa su 
participación en las exportaciones brasileñas, mientras Rusia gana participación entre 2006 y 2010, para luego sólo concentrar el 4\%.

Uruguay es estable en términos de mercados a los que accede con estos productos, no obstante, a través del tiempo se reduce el número de mercados relevantes destacándose entre todos, Hong Kong.

\section{Tabla 8. Posición arancelaria 050400. Exportaciones por país.}

Brasil

\begin{tabular}{|c|c|c|c|c|c|}
\hline \multicolumn{2}{|c|}{2006} & \multicolumn{2}{c|}{2010} & \multicolumn{2}{c|}{2015} \\
\hline País & Participación & País & Participación & País & Participación \\
\hline Hong Kong & $53 \%$ & Hong Kong & $54 \%$ & Hong Kong & $67 \%$ \\
\hline Italia & $10 \%$ & Rusia & $15 \%$ & - & - \\
\hline España & $7 \%$ & Ucrania & $7 \%$ & - & - \\
\hline Alemania & $6 \%$ & - & - & - & - \\
\hline Rusia & $5 \%$ & - & - & - & $67 \%$ \\
\hline Total & $81 \%$ & Total & $77 \%$ & Total & 82 \\
\hline $\begin{array}{c}\text { Destinos } \\
\text { totales }\end{array}$ & 51 & $\begin{array}{c}\text { Destinos } \\
\text { totales }\end{array}$ & 83 & Destinos & totales \\
\hline
\end{tabular}

\begin{tabular}{|c|c|c|c|c|c|}
\hline \multicolumn{2}{|c|}{ Uruguay } & \multicolumn{2}{c|}{2015} \\
\hline País & Participación & País & Participación & País & Participación \\
\hline Polonia & $20 \%$ & Hong Kong & $37 \%$ & Hong Kong & $63 \%$ \\
\hline Hong Kong & $18 \%$ & Italia & $21 \%$ & Italia & $13 \%$ \\
\hline Italia & $16 \%$ & Alemania & $17 \%$ & Alemania & $8 \%$ \\
\hline España & $14 \%$ & España & $10 \%$ & - & - \\
\hline Alemania & $13 \%$ & - & - & - & - \\
\hline Total & $81 \%$ & Total & $85 \%$ & Total & $83 \%$ \\
\hline $\begin{array}{c}\text { Destinos } \\
\text { totales }\end{array}$ & 29 & Destinos & 28 & Destinos & totales \\
\hline
\end{tabular}

Paraguay

\begin{tabular}{|c|c|c|c|c|c|}
\hline \multicolumn{2}{|c|}{2006} & \multicolumn{2}{c|}{2010} & \multicolumn{2}{c|}{2015} \\
\hline País & Participación & País & Participación & País & Participación \\
\hline Perú & $31 \%$ & Perú & $22 \%$ & Hong Kong & $35 \%$ \\
\hline Alemania & $12 \%$ & Vietnam & $16 \%$ & Rusia & $17 \%$ \\
\hline Suiza & $10 \%$ & Hong Kong & $12 \%$ & Vietnam & $15 \%$ \\
\hline Brasil & $5 \%$ & España & $7 \%$ & Argentina & $7 \%$ \\
\hline España & $5 \%$ & Angola & $5 \%$ & Italia & $6 \%$ \\
\hline Portugal & $5 \%$ & - & - & Francia & $5 \%$ \\
\hline Total & $67 \%$ & Total & $62 \%$ & Total & $84 \%$ \\
\hline Destinos totales & 29 & Destinos totales & 29 & Destinos totales & 31 \\
\hline
\end{tabular}

Fuente: Elaboración propia con base en UN Comtrade. 
Finalmente, Paraguay muestra dispar presencia regional; alcance a la UE y creciente participación de Hong Kong y Rusia. Esto último se acerca a lo ocurrido con los restantes países del Mercosur aunque, con menor porcentaje acumulado de exportaciones. En paralelo el número de destinos totales mantiene cierta estabilidad. En este segmento del mercado vacuno también hay un número acotado de países con participaciones de al menos el 5\% del mercado pero la acumulación de importaciones que logran es cercana al $60 \%$ del total. Dentro de ellos se destacan distintos países de la UE, estando Alemania como principal comprador. También Estados Unidos y México están presentes en las puntas del período y Japón conserva su cuota de mercado en los distintos años analizados. Surge China en 2010 y 2015 como importador significativo con una participación de mercado del 8\%. Para los tres países del Mercosur analizados, Hong Kong es un destino muy importante y en el caso de Brasil termina siendo un gran adquirente de sus exportaciones, en desmedro de la participación de países de la UE. Uruguay y Paraguay mantienen una cartera de importadores más diversificada, teniendo como compradores relevantes a países de la UE como Alemania e Italia, según cada caso.

\subsection{Las demás preparaciones y conservas de carne o sangre}

En este rubro dentro del mercado mundial de carne bovina ningún país del Mercosur mantuvo una performance de crecimiento en el tiempo.

\section{Conclusiones}

A partir del análisis de los flujos comerciales de carne vacuna en el período 20062015 se observa que gran parte del comercio se desarrolla entre los países de la misma región geográfica, destacándose en esta distribución tres grandes áreas: la región europea, región del norte de América y Oceanía en conjunto con los países árabes y asiáticos.

A diferencia de este patrón, dentro de los grandes jugadores globales, surgen casos como el de Estados Unidos, el Cono Sur de América y los países de Oceanía cuyo comercio logra insertarse en países alejados.

Por otro lado, se registra una fuerte concentración de países oferentes y demandantes que capturan la mayor parte del comercio. Si bien en gran parte de los productos cárnicos se presenta una gran diversificación de mercados, sólo unos pocos destinos adquieren significancia para los países oferentes.

Esta estructura de comercio presenta facilidades en términos de negociaciones comerciales con países socios relevantes y abre un conjunto de oportunidades comerciales en mercados a los que se accede actualmente pero con una baja participación de mercado.

Al analizar la situación particular de los países del Mercosur, el comportamiento de Argentina durante los años analizados se muestra declinante en términos de participación de mercado mundial para la carne fresca y refrigerada, congelada, parte de despojos comestibles y preparaciones y conservas de carne y despojos. Estos resultados se manifiestan más notoriamente cuando se los comparara con lo ocurrido con los distintos países del Mercosur. Incluso en los segmentos en los que Argentina pudo acompañar el dinamismo mundial, su performance fue la menos 
destacada del Cono Sur.

En este contexto, en líneas generales, los países del Mercosur que incrementaron su cuota de mercado lo hicieron gracias a una concentración de destinos relevantes, destacándose Rusia, Hong Kong, China y en algunos casos Angola e Israel, es decir, una orientación exportadora que traspasa la cercanía geográfica y en varios casos, una disminución de mercados de exportación relevantes. En paralelo, no se observa un aumento sistemático de destinos de exportación, aunque dado el número de mercados totales queda abierta la posibilidad de potenciar destinos a los que actualmente se accede pero con bajas cuotas de mercado.

\section{Referencias bibliográficas}

Baldwin, R. (2012). Global supply chain: why they emerged, why they matter and where they are going. Londres, Inglaterra: Center for Economic Policy Reseach (CEPR).

Bianchi, E. y Piñeiro, M. (2017). A proposal for the Elimination of Export Restrictions on Food Products. En Piñeiro, V. y Piñeiro, M. (Eds.), Agricultural Trade Interests and Challenges at the WTO Ministerial Conference in Buenos Aires: A Southern Cone Perspective. Buenos Aires, Argentina: Bolsa de Cereales, Fundación INAI, GPS, IICA, ICTSD e IFPRI.

Bianchi, E. y Szpak, C. (2015). Mercados de exportación de productos agroindustriales actuales y futuros. Grupo de Productores del Sur (GPS). Recuperado de: https://grupogpps.org/web/mercados-actuales-y-futuros-de-exportacion-deproductos-agroindustriales-por-eduardo-bianchi-y-carolina-szpak/

Bianco, C., Moldovan, P. y Porta, F. (2008). La internacionalización de las empresas brasileñas en Argentina. Documento de proyecto. Buenos Aires, Argentina: CEPAL.

CIECTI [Centro Interdisciplinario de Estudios en Ciencia, Tecnología e Innovación]. (2012). Análisis tecnológico sectorial. Documento de trabajo. Buenos Aires, Argentina: Ministerio de Ciencia y Técnica de la Nación.

De Las Carreras, A. (2005). El Despertar Ganadero. El mundo, una gran oportunidad. Buenos Aires, Argentina: Siglo XXI.

Errecart, V. (2015). Análisis del mercado mundial de carnes. Documento de trabajo del Centro de Economía Regional (CERE). Buenos Aires, Argentina: Escuela de Economía y Negocios de la Universidad Nacional de San Martín. Recuperado de: http://www.unsam.edu.ar/escuelas/economia/economia regional/CERE\%20-\%20Mayo\%20-\%202015.pdf

IPCVA [Instituto de la Promoción de la Carne Vacuna Argentina]. (2014). Informe de Mercados internacionales de Carne Vacuna. Evolución reciente $y$ tendencias de los principales mercados. Recuperado de: $\quad$ http://www.ipcva.com.ar/documentos/1309_1402323969_ informedemercadosinternacionalesdecarnebovina2013.pdf 
Llach, J. (2012). La demanda mundial de alimentos, 2010-2020 y después. Buenos Aires, Argentina: Fundación Producir Conservando.

Luchetti, C. (2011). Valor agregado en la comercialización de la carne. Ganadería. Recuperado de: https://www.engormix.com/ganaderia-carne/articulos/ mercado-de-la-carne-en-argentina-t28863.htm

Ministerio de Hacienda (2018). Informes de Cadenas de Valor: Cárnica-Vacuna. Año 3, núm. 35. Buenos Aires, Argentina: Subsecretaría de Programación Microeconómica de la Secretaría de Política Económica. 